\title{
Representation of Future and Previous Spatial Goals by Separate Neural Populations in Prefrontal Cortex
}

\author{
Aldo Genovesio, Peter J. Brasted, and Steven P. Wise \\ Laboratory of Systems Neuroscience, National Institute of Mental Health, National Institutes of Health, Bethesda, Maryland $20892-4401$
}

\begin{abstract}
The primate prefrontal cortex plays a central role in choosing goals, along with a wide variety of additional functions, including shortterm memory. In the present study, we examined neuronal activity in the prefrontal cortex as monkeys used abstract response strategies to select one of three spatial goals, a selection that depended on their memory of the most recent previous goal. During each trial, the monkeys selected a future goal on the basis of events from the previous trial, including both the symbolic visual cue that had appeared on that trial and the previous goal that the monkeys had selected. When a symbolic visual cue repeated from the previous trial, the monkeys stayed with their previous goal as the next (future) goal; when the cue changed, the monkeys shifted from their previous goal to one of the two remaining locations as their future goal. We found that prefrontal neurons had activity that reflected either previous goals or future goals, but only rarely did individual cells reflect both. This finding suggests that essentially separate neural networks encode these two aspects of spatial information processing. A failure to distinguish previous and future goals could lead to two kinds of maladaptive behavior. First, wrongly representing an accomplished goal as still pending could cause perseveration or compulsive checking, two disorders commonly attributed to dysfunction of the prefrontal cortex. Second, mistaking a pending goal as already accomplished could cause the failures of omission that occur commonly in dementia.
\end{abstract}

Key words: behavioral neurophysiology; strategies; prospective memory; rules; frontal lobe; output monitoring

\section{Introduction}

The prefrontal cortex (PF) contributes to many cognitive operations, including goal selection and short-term memory. Several neurophysiological studies have assessed the role of the PF in short-term memory for places (Fuster and Alexander, 1971; Kojima and Goldman-Rakic, 1982; Funahashi et al., 1989, 1993; Quintana and Fuster, 1993; Wilson et al., 1993; Goldman-Rakic, 1996; Rao et al., 1997; Rainer et al., 1998; Constantinidis et al., 2001; Lebedev et al., 2004; Takeda and Funahashi, 2004), objects (Wilson et al., 1993; Miller et al., 1996; Rao et al., 1997; Rainer et al., 1998; Sawaguchi and Yamane, 1999; Hasegawa et al., 2004), or stimulus features (Kim and Shadlen, 1999; Romo et al., 1999). Others have described the prospective coding of places (Fukushima et al., 2004) or objects (Rainer et al., 1999) that will serve as future goals. In a study of the role of the PF in the implementation of abstract response strategies (Genovesio et al., 2005), we observed that different subpopulations of PF neurons encoded the memory for previous spatial goals and the places chosen as future spatial goals.

Received Feb. 16, 2006; revised May 10, 2006; accepted May 31, 2006.

This work was supported by the Intramural Research Program of the National Institutes of Health-National Institute of Mental Health (Grant Z01MH-01092-27). We thank Alex Cummings for the histological material, James Fellows for help training the animals, and Dr. Andrew Mitz for assistance with data analysis and engineering. Dr. Jerald D. Kralik suggested the specific method used for the neuron-dropping analysis. Drs. Silvia A. Bunge, Rony Paz, Veit Stuphorn, and Eilon Vaadia provided useful comments on a previous version of this manuscript.

Correspondence should be addressed to Dr. Steven P. Wise, Laboratory of Systems Neuroscience, National Institute of Mental Health, National Institutes of Health, Building 49, Room B1EE17, 49 Convent Drive, MSC 4401, Bethesda, MD 20892-4401. E-mail: stevenwise@mail.nih.gov.

DOI:10.1523/JNEUROSCI.0699-06.2006

Copyright $\odot 2006$ Society for Neuroscience $\quad$ 0270-6474/06/267305-12\$15.00/0
In published neurophysiological work on PF, it has been difficult to contrast the activity encoding previous versus future goals. For example, in spatial delayed-response tasks (Fuster and Alexander, 1971; Kojima and Goldman-Rakic, 1982; Funahashi et al., 1989; Takeda and Funahashi, 2004) and in associative learning tasks (Asaad et al., 1998; White and Wise, 1999; Fuster et al., 2000; Pasupathy and Miller, 2005), the location of any previous goal was irrelevant to the choice of the next one, which was cued separately on each trial. In the spatial alternation task, the previous goal indicated the future one, but the use of only two relevant locations at one time precluded any interpretation in terms of previous versus future goals. In a left-right alternation task (Niki, 1974a,b), for example, the preference of a neuron for the left location as the future goal could not be distinguished from a preference for the right location as the previous goal. The present experiment could distinguish signals for previous versus future spatial goals because they were processed during different delay periods, as well as at other times during a trial, and because three places, rather than two, served both as goals and as the basis for selecting other goals.

\section{Materials and Methods}

We studied two adult, male rhesus monkeys (Macaca mulatta), $8.8 \mathrm{~kg}$ and $7.7 \mathrm{~kg}$. They sat in a primate chair, with their heads fixed, and faced a video screen $32 \mathrm{~cm}$ away. All procedures conformed to the Guide for the Care and Use of Laboratory Animals and were approved by the appropriate Institutional Animal Care and Use Committee. We used a fluidcontrolled diet to motivate the monkeys to perform the task, described below, for positive reinforcement. The monkeys performed two tasks: the strategy task and the mapping task (Genovesio et al., 2005). 


\section{Behavioral methods}

Sequence of events

Figure $1 A$ shows the sequence of events in the strategy task. After a $2.5 \mathrm{~s}$ intertrial interval (Fig. $1 \mathrm{A1}$ ), a $0.7^{\circ}$ (visual angle) white circle, the "fixation spot," appeared at the center of the video screen. Once the monkey fixated this location, three potential goals $\left(2.2^{\circ}\right.$ unfilled white squares) came on: $14^{\circ}$ left, right, and up from the fixation spot (Fig. 1 A2). The monkeys were required to maintain fixation $\left( \pm 7.5^{\circ}\right)$ for $1.0 \mathrm{~s}$, and these parts of the task were called "fixation periods." Note, however, that the monkeys also fixated some location during other task periods.

Next, a symbolic visual cue appeared at the fixation spot for 1.0, 1.5, or $2.0 \mathrm{~s}$ (Fig. 1A3). Both the cue and its duration were pseudorandomly selected from three possibilities on each trial. Each symbolic cue comprised two superimposed ASCII characters, usually of different colors. One character was usually larger than the other, and together they had approximately the same size as the goal squares. (Note that Fig. $1 \mathrm{~A}$ is not to scale.) We did not attempt to determine which features of the symbolic cues were responsible for the activity of a cell because considerable previous neurophysiological research has shown that complex, highdimensional visual stimuli elicit robust activity from PF neurons (Miller et al., 1996), which proved adequate for the present purpose.

The disappearance of the symbolic cue served as the trigger (or "go") stimulus (Fig. 1A4). The monkeys then made a saccadic eye movement (Fig. 1 A5, arrow) to one of the three potential goals $\left( \pm 6.7^{\circ}\right)$ within a $2.0 \mathrm{~s}$ limit. In practice, their choice of goal and saccadic eye movements occurred much faster (see Results). The monkeys were required to continue fixating the chosen goal $\left( \pm 6.7^{\circ}\right)$ for $1.0 \mathrm{~s}$, called the "goal hold time" (Fig. 1A6), after which all three targets became solid white (Fig. 1A7). If appropriate, a $0.1 \mathrm{ml}$ drop of fluid reward was delivered $0.5 \mathrm{~s}$ later. On both rewarded and unrewarded trials, the goal squares disappeared from the screen at that time and an intertrial interval began (Fig. $1 A 1, A 8)$.

\section{Trial types and terminology}

All trials in both the strategy task and the mapping task conformed to the sequence of events described above. In the strategy task, there were two trial types, two principal fixation periods, and three relevant strategies. We called the two trial types "first-chance trials" (Fig. 1 $A 1-A 7$ ) and "second-chance trials" (Fig. 1A8-A10). Both types of trials included a pre-cue fixation period, hence the two principal fixation periods. The Fix I period occurred on first-chance trials (Fig. 1A2); the Fix II period occurred on second-chance trials (Fig. 1A9). As for the three strategies, on first-chance trials, the monkeys chose a future goal based on one of two response strategies, called "repeat-stay" and "change-shift," described below. On second-chance trials, they chose a goal based on a "lose-shift" strategy, also described below.

In what follows, the phrase "previous goal" refers to the most recently chosen goal, except where noted, and "future goal" refers to the next goal that the monkeys will choose, which they did on each current trial.

Strategy task. On each first-chance trial, a symbolic cue was selected pseudorandomly from a set of three cues, which differed from any cues the monkeys had seen in previous sessions or blocks. Thus, for each neuron, the monkeys had not seen any of the three cues before the be- ginning of a block of $\sim 100$ trials. The first trial in a block was a special case, but in all subsequent first-chance trials, the monkeys had to apply the repeat-stay and change-shift strategies to gain rewards. The repeatstay strategy required the monkeys to choose the previous goal again whenever the symbolic cue repeated from the previous trial (called "repeat trials"), and the change-shift strategy required them to reject the previous goal whenever the cue changed from the previous trial (called "change trials"). In Figure 1B1, for example, the cue repeated from the previous trial, hence the right goal was correct, according to the repeatstay strategy. When the cue changed to one of the other two symbolic cues in the set (Fig. 1B2,B3), both the top and left goals were correct, according to the change-shift strategy. A correct repeat-stay choice always produced a prompt reward (Fig. 1 B1), but a correct change-shift choice did so for only one of the two possibilities (Fig. 1 B2, top goal), which was selected pseudorandomly in advance of each first-chance trial. After a reward, the first-chance trial ended.

After each unrewarded choice, the monkeys had an unlimited number of second-chance trials in which the sequence of events matched that of first-chance trials. After an intertrial interval (Fig. 1A8) and the Fix II period (Fig. 1A9), the symbolic cue from the immediately preceding first-chance trial reappeared (Fig. 1A10). Thereafter, a second-chance trial proceeded exactly as did a first-chance trial. [Note that Figure $1 \mathrm{~A}$ shows only the initial events of second-chance trials (Fig. 1A8-A10) and omits the events corresponding to Figure $1 A 4-A 7$.] On second-chance 
A

First-chance trials sorted by previous goal
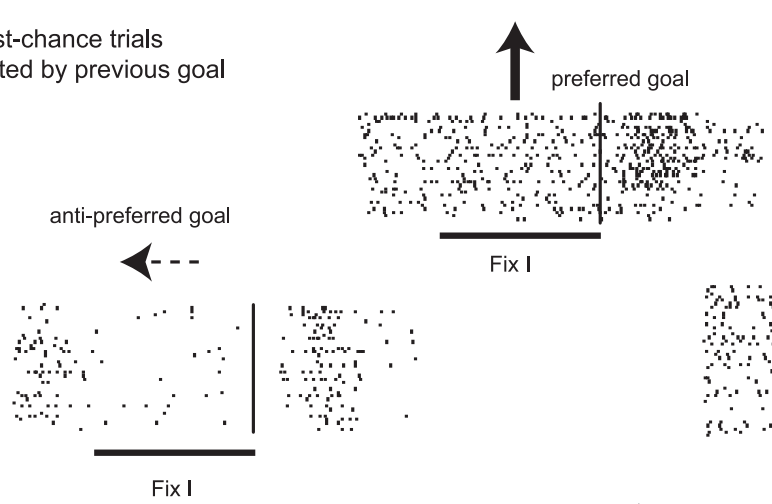

Fix I
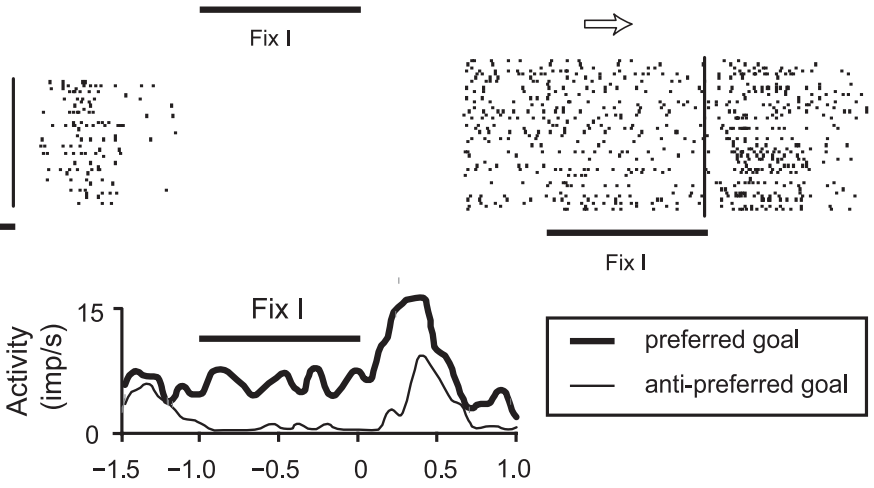

\section{B}

Second-chance trials sorted by future goal
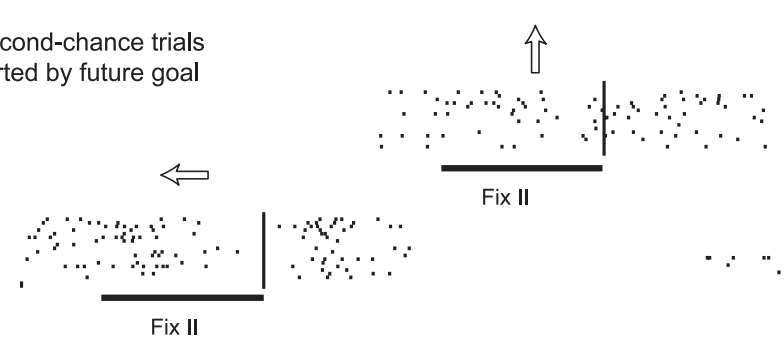

Fix II

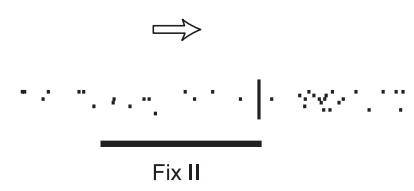

C

First-chance trials sorted by future goal
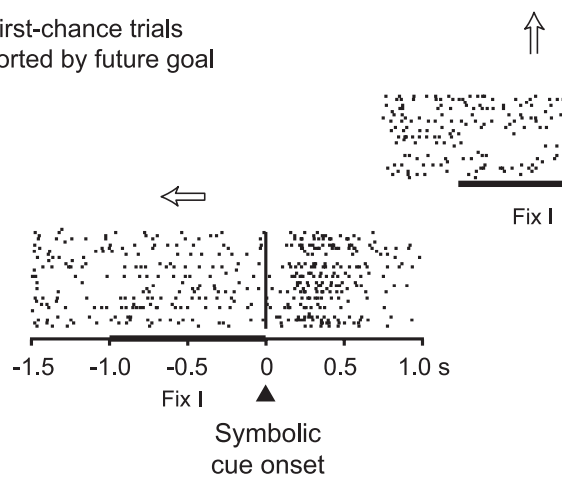

Figure 2. PF neuron with activity related to the previous goal. $\boldsymbol{A}$, First-chance trials sorted into raster displays according to the previous goal. Each raster shows activity on the current, first-chance trial, aligned on the onset of the symbolic cue (black vertical line). The arrows show the previous-goal location relative to the central fixation point. During the Fix I period, the preferred previous-goal location was the top one (solid black arrow), and the anti-preferred goal was the left one (dashed arrow). The plot below the rasters compares average activity for these two previous goals. $\boldsymbol{B}$, The same cell showed no goal selectivity for future goals during the Fix II period of second-chance trials. $C$, The same cell also showed no goal selectivity for future goals during the Fix I period of first-chance trials (matching $\boldsymbol{A}$ ). imp, Impulses.

trials, the monkeys produced a reward by selecting the goal that remained after eliminating the two most recent ones. In Figure 1 B3, the monkeys needed to reject both the right goal, which had produced a reward on the previous trial, and the left goal, which had failed to produce a reward on the first-chance trial. Accordingly, a choice of the top goal produced a reward on the second-chance trial (a lose-shift strategy). For this study, we analyzed only correctly performed second-chance trials that immediately followed change trials, as illustrated in Figure 1 B3.
This experimental design, although intended for other purposes (Genovesio et al., 2005), allowed us to contrast neural activity reflecting previous and future goals, based on one plausible assumption. We examined PF activity during two periods of stable, central fixation before the appearance of the symbolic cue: the Fix I and Fix II periods. To perform the strategy task, the monkeys had to remember their previous goal during the Fix I period of the strategy task but could not yet have chosen their future goal. Thus, cells representing the previous goal should have done so during the Fix I period. Then came the symbolic cue and goal choice for a first-chance trial, which, when unrewarded, was followed by the Fix II period of a secondchance trial. We assume that the monkeys had chosen their goal before the Fix II period, soon after the nonreward "event." Accordingly, cells representing the future goal should have done so during the Fix II period. We could test this assumption by examining future-goal selectivity at different times during the strategy task (e.g., after the symbolic cue in first-chance trials) and in another task (the mapping task).

Mapping task. A block of $\sim 100$ trials in the mapping task followed performance of the strategy task. In the mapping task, the monkeys responded to symbolic cues according to three cue-goal mappings. At the beginning of a block of trials, all three mappings were unknown, although the cues were the same as in the justcompleted block of trials on the strategy task. As a block of mapping trials progressed, the monkeys learned, by trial and error, which one of the three goals to choose in response to each symbolic cue. The present analysis was confined to the trials performed after the monkeys had learned the mappings, which occurred within 10 trials for each cue-goal pair in these highly experienced monkeys, corresponding to $90 \%$ correct performance or better. The sequence of events in the mapping task matched that in the strategy task (Fig. 1A1-A7). Most important for the present purpose, in the mapping task, each symbolic cue instructed a response to one of the three goals, regardless of the previous goal or the previous cue. In the strategy task, as described above, a given symbolic cue did not instruct any specific goal consistently. Instead, the future goal depended not only on the symbolic cue from the current trial but also on both the cue and goal from the previous trial.

\section{Surgery}

Using aseptic techniques and isofluorane anesthesia ( $1-3 \%$, to effect), we made a $27 \times 36 \mathrm{~mm}$ craniotomy over the right frontal lobe of each monkey. Then, after cleaning the surgical field, we implanted several titanium bone screws into the surrounding bone and attached a recording chamber, along with a head-restraint device, to those screws with acrylic cement. Postoperative analgesia was given to relieve discomfort for a period of $3-5 \mathrm{~d}$, followed by a gradual return to a fluid-controlled diet.

\section{Data collection methods}

We monitored eye position with an infrared oculometer (Bouis Instruments, Karlsruhe, Germany) at 500 or 1000 samples/s. Single-unit po- 
tentials were isolated with quartz-insulated platinum-iridium electrodes (impedance, $0.5-1.5 \mathrm{M} \Omega$ at $1 \mathrm{kHz}$ ), advanced into the cortex by a 16electrode microdrive with independent control of each electrode (Thomas Recording, Giessen, Germany). The signal from each electrode was filtered with a bandpass of $0.6-6.0 \mathrm{kHz}$, amplified, and discriminated using a Multispike Detector (Alpha-Omega Engineering, Nazareth, Israel) or a Multichannel Acquisition Processor (Plexon, Dallas, TX). When using the latter, neuronal waveforms were always resorted with the Offline Sorter (Plexon). A noncommercial software package, CORTEX, was used to control behavior and collect data. Neuronal populations were accumulated in daily sessions, rather than simultaneously.

\section{Neuronal analysis}

We used custom programs and SPSS (SPSS, Chicago, IL) for analysis. To compute mean discharge rates for illustrative purposes only, we averaged, across trials for each cell, the reciprocal of the interspike intervals in $20 \mathrm{~ms}$ bins. The illustrated population averages were calculated as the means of these single-cell averages.

To identify activity related to the location of the future goal, we performed a one-way ANOVA $(\alpha=0.05)$ for activity during the fixation period of second-chance trials, the Fix II period, with location of the future goal as the factor. We used a time interval from 80 to $1000 \mathrm{~ms}$ after the onset of the fixation period. This analysis included only the cells that had at least five trials for each goal in second-chance trials. The average number of trials used in these analyses was 12 and 9 for each future goal in monkeys 1 and 2, respectively. This subpopulation comprised 259 and 568 neurons in monkeys 1 and 2, respectively, and was identical to one of the two subpopulations used in the previous-goal analysis (see below). We also performed a two-way ANOVA, with future and previous goals as factors, to examine possible interactive effects. The number of cells with significant interactive effects did not exceed the number expected by chance variation and is not reported.

To identify activity related to the location of the previous goal, we examined activity during the Fix I period ( $80-1000 \mathrm{~ms}$ after its onset) and performed a two-way ANOVA with a previous cue and a previous goal as factors. This analysis was performed on two cortically coextensive subpopulations of neurons, one matching the population used for the future-goal analysis, described above. These cells averaged 37 trials per goal in both monkeys. A larger subpopulation, made up of 628 neurons in monkey 1 and 705 neurons in monkey 2, lacked the requirement for five trials per goal in second-chance trials and thus included more of the recorded neurons.

Additionally, we evaluated whether PF cells with future-goal selectivity during second-chance trials also showed that selectivity for the same, future goal in the mapping task and in first-chance trials of the strategy task. To this end, we measured activity from 400 to $1000 \mathrm{~ms}$ after the onset of the symbolic cue in first-chance trials in both the mapping and strategy tasks (Fig. 1A3). This task period was selected because our previous study (Genovesio et al., 2005) indicated that the decision as to the future goal had taken place by that time. For both tasks, we performed a one-way ANOVA with future-goal location as the factor.

Neuron-dropping analysis was used to estimate how well ensembles of PF neurons represented the previous and future goals (Laubach et al., 2000; Foffani and Moxon, 2004). This calculation began with the total subpopulation of a given type (e.g., neurons that ANOVA identified as encoding a previous-goal location). For a given subpopulation, consisting of $n$ cells, we selected one test trial randomly from each neuron and used all of the remaining trials to assemble a look-up table of firing rates. This table amounted to a vector of average discharge rates, with an average discharge rate for each neuron and each of the three goal locations. For the selected set of test trials, based on one trial (and thus one goal location) for each neuron, we computed an estimate of which location was the goal on that trial, defined as the goal with the smallest Euclidean distance between the set of test trials and the look-up table. We then repeated this procedure 1200 times to determine how often this computation led to a correct estimation of the goal, separately for future and previous goals. Next, we eliminated a randomly selected neuron from the remaining population and repeated the process, producing an estimate for $n-1$ cells, iteratively, until only one neuron remained. This neuron-

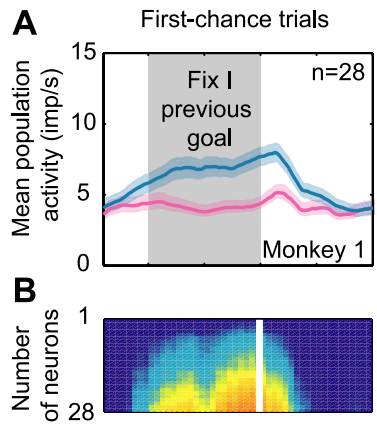

Second-chance trials

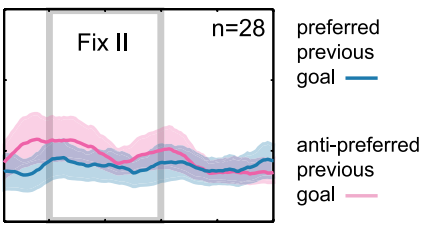

C
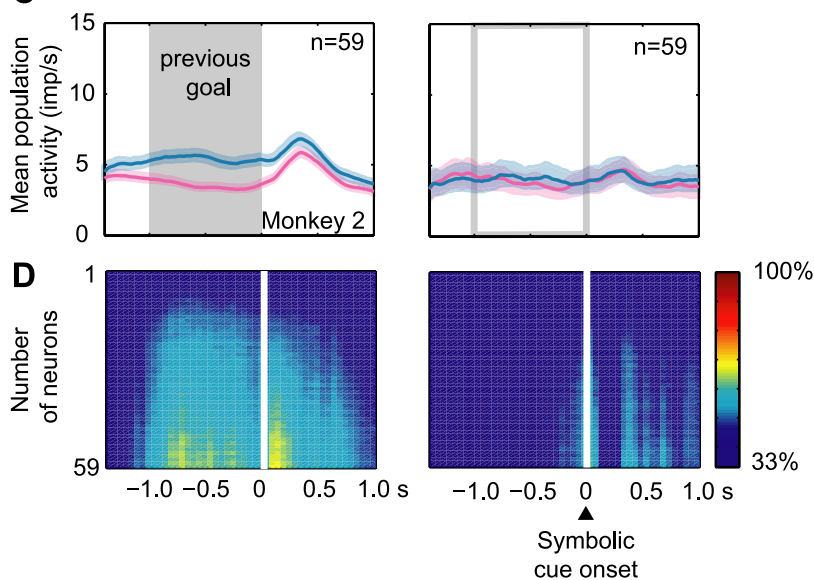

Figure 3. Previous-goal selectivity at the population level. $\boldsymbol{A}, \boldsymbol{B}$, Monkey 1.C, D, Monkey 2.A, C, Average population histograms, with $95 \%$ confidence limits (shaded area), for the preferred previous goals (blue) and the anti-preferred previous goals (magenta), as determined during the Fix I period of first-chance trials. This subpopulation of PF neurons showed selectivity for previous goal (left) and a lack of selectivity for the same location when it was the future goal (right). $\boldsymbol{B}, \boldsymbol{D}$, Neuron-dropping analysis for all possible ensemble sizes. The percentage of accurate estimations is indicated by color, with reds and yellows indicating relatively high accuracy and blues indicating lower accuracy, down to chance level (33\%). Neuron-dropping curves for activity averaged over the entire fixation period are shown in supplemental Figure 2 (available at www.jneurosci.org as supplemental material). This subpopulation of PF neurons encoded the previous goal (left) but not the future one (right). Note that the accuracy of the previousgoal estimation decreased within $500 \mathrm{~ms}$ after the appearance of the symbolic cue, which suggests that information about previous goals was rapidly integrated with other information, such as the previous symbolic cue and the strategy to be used (see also Fig. $9 A, C$. imp Impulses.

dropping procedure was repeated 50 times, using different randomly selecting lists of neurons to drop, which yielded an average goal estimation as a function of ensemble size.

\section{Histological analysis}

Near the end of physiological data collection, we made electrolytic lesions (15 $\mu \mathrm{A}$ for $10 \mathrm{~s}$, anodal current) at two depths in selected locations. After $\sim 10 \mathrm{~d}$, the animal was deeply anesthetized and perfused through the heart with formaldehyde-containing fixative. The brains were later sectioned in the coronal plane and stained for Nissl substance for cytoarchitectonic analysis (Genovesio et al., 2005). We plotted the surface projections of the recording sites by reference to the recovered electrolytic lesions and the marking pins inserted at the time of the perfusion (Fig. $1 C$ and supplemental Fig. 1, available at www.jneurosci.org as supplemental material).

\section{Results}

The monkeys performed the strategy task very accurately. On first-chance trials, the monkeys performed repeat trials at $>95 \%$ correct (96.8 and 96.0\% correct for monkeys 1 and 2, respec- 
A

First-chance trials sorted by previous goal
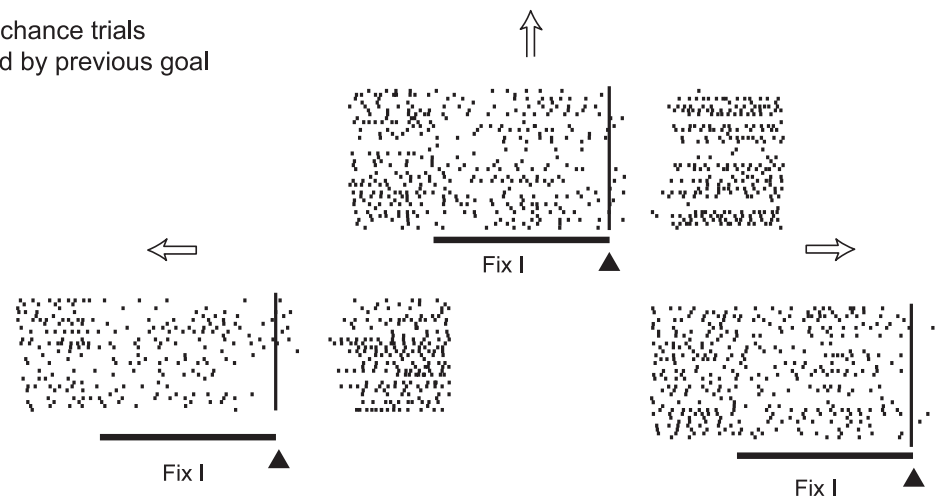

\section{B}

Second-chance trials sorted by future goal
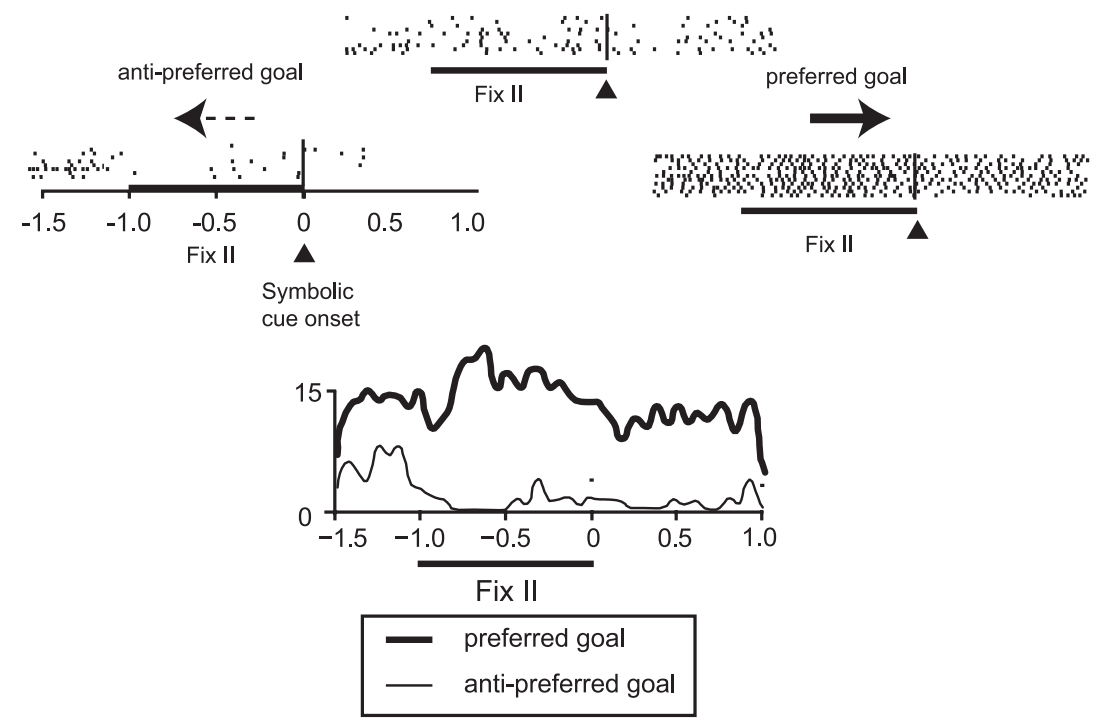

Figure 4. PF neuron with future-goal selectivity. The format is as in Figure 2. Note that this neuron represented the future goal $(\boldsymbol{B})$ but not the previous goal $(\boldsymbol{A})$.

tively). On change-shift trials, the monkeys made change-shift choices correctly $>98 \%$ of the time $(98.9$ and $98.3 \%$ correct the two monkeys). On second-chance trials, the monkey performed slightly less accurately but, nevertheless, exceeded 90\% correct (93.5 and $92.3 \%$ correct).

The movement parameters and reaction times have been reported previously (Genovesio et al., 2005). For first-chance trials, although the monkeys had a $2 \mathrm{~s}$ time window within which to respond, they did so in a small fraction of that period: $285 \pm 47$ and $279 \pm 93 \mathrm{~ms}$ (saccadic reaction time \pm SD) for the changeshift choices in monkeys 1 and 2, respectively, and $288 \pm 57$ and $281 \pm 96 \mathrm{~ms}$ for repeat-stay choices. For second-chance trials, the monkeys responded in $295 \pm 54$ and $265 \pm 86 \mathrm{~ms}$.

The neuronal database for the present analysis consisted of 1456 isolated single neurons, 700 from monkey 1 and 756 from monkey 2. Figure $1 C$ shows the recording locations in both the dorsolateral PF (PFdl), mainly area 46, and dorsal PF (PFd), spanning areas 6,8 , and 9 . The properties described below did not differ between these two regions $\left(\chi^{2}=3.1 ; p>0.2\right)$ (see supplemental Fig. 1, available at www.jneurosci.org as supplemental material), so we combined them for this report. We found cells

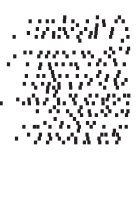

with selectivity for the previous goal, others with selectivity for the future goal, and still others with selectivity for both, which we term "hybrid" selectivity. In what follows, we first describe the characteristics of previous-goal selectivity and then do likewise for future-goal selectivity. Then we consider the relative frequencies of these two classes of selectivity in relation to hybrid selectivity. Finally, we consider the time course over which these goaldependent signals develop and dissipate, their relationship to the strategies used, activity on error trials, and cue selectivity.

\section{Previous-goal selectivity}

Figure 2 shows a PF neuron selective for the previous goal. During the Fix I period, which occurred on first-chance trials, the monkey had to remember the previous goal but could not yet choose its future one. This cell showed significantly higher fixation-period discharge rates when the previous goals had been the top and right ones, compared with the left goal (Fig. $2 A)$. We designated the goal associated with the highest discharge rate as the "preferred goal" (Fig. $2 \mathrm{~A}$, solid arrow) and the one with the lowest activity as the "antipreferred goal” (Fig. 2A, dashed arrow). The average peri-event time plots show the time course of neuronal discharge for both (Fig. 2A, bottom). This neuron had no selectivity for the future goal, as seen in the Fix II period of second-chance trials (Fig. $2 B$ ), by which time the monkeys presumably had chosen their next goal. (See the Discussion for a consideration of this assumption.) When the same data shown in Figure $2 A$ was re-sorted according to the future goal, the one that was ultimately chosen on the current trial, the cell showed no significant difference among the three goal locations during the Fix I period (Fig. 2C), in marked contrast to the selectivity observed when the data were sorted according to the previous goal (Fig. 2A).

We analyzed the 827 PF neurons that met the inclusion criterion of at least five trials for each goal: 259 cells from monkey 1 and 568 from monkey 2. Of these 827 cells, 108 (13\%) showed previous-goal selectivity by ANOVA: 37 in monkey 1 and 71 in monkey 2. Most of these cells showed no selectivity for the future goal, but removing those few that did, called hybrid cells, reduced the size of the tested subpopulation to 28 and 59 cells in monkeys 1 and 2, respectively. To test further the separation between neuronal subpopulations coding for previous versus future goals, we performed two analyses at the population level: activity averages and neuron dropping (see Materials and Methods). Figure 3, A and $C$, shows population averages for cells encoding a previous goal, for monkey 1 (Fig. 3A) and monkey 2 (Fig. 3C), separately. After classifying these cells as selective for previous goals by ANOVA, we evaluated whether they might also have encoded the previous goal as a location per se, regardless of whether that location served as a previous goal or a future goal. Although these 


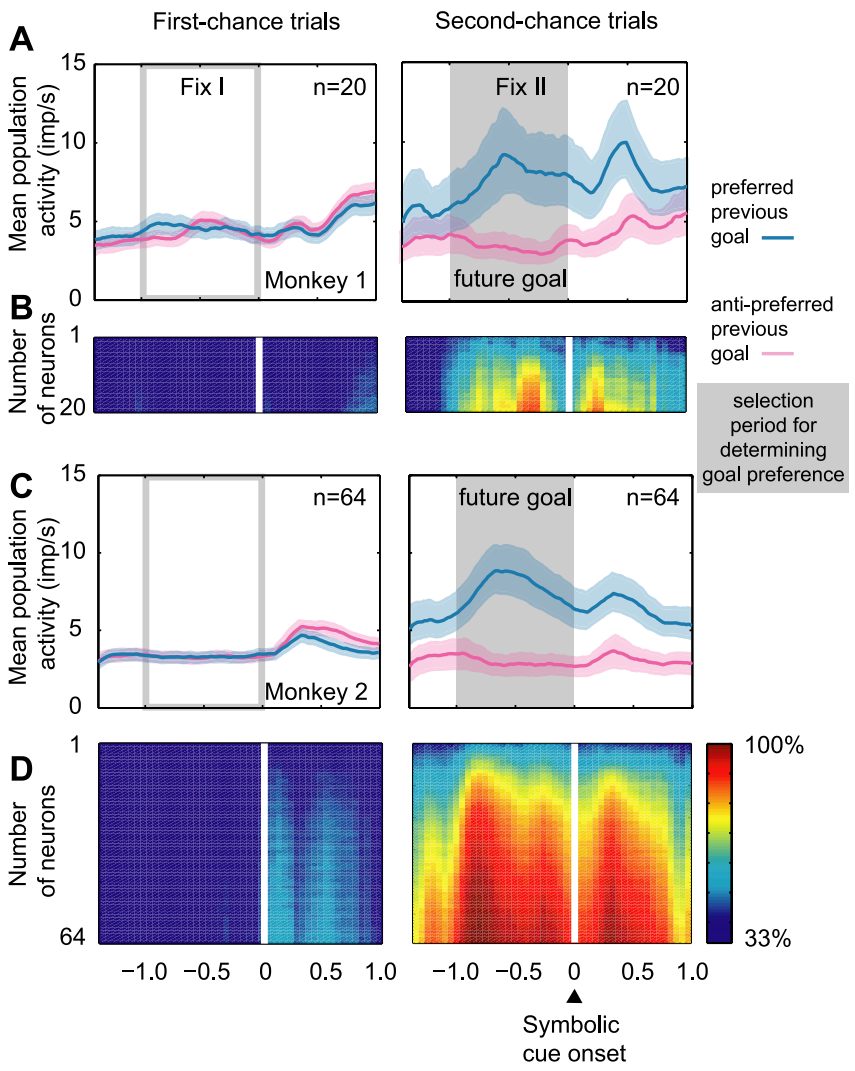

Figure 5. Future-goal-selective population. The format is as in Figure 3. Note that this subpopulation represented the future goal (right column), but not the previous goal (left column). imp, Impulses.

cells did not show a significant relationship with future goals (by ANOVA), it remained possible that they encoded those locations as a population. For this purpose, we sorted trials into those for the preferred and anti-preferred goals using data from the Fix I period (Fig. $3 A, C$, gray shading) and applied these designations to the Fix II period (Fig. $3 A, C$, gray boxes). This subpopulation of cells, which encoded the previous goal (Fig. $3 A, C$, left, blue vs magenta curves), showed little or no capacity for encoding the same locations when they served as future goals (Fig. $3 A, C$, right).

Unlike population averages, neuron-dropping analysis expresses the ability to estimate a location from the activity of a neuronal ensemble, as a function of its size, and does not attach any special significance to the preferred spatial location of a cell, its tuning function, or whether its activity for a given location increases or decreases relative to other locations. The analysis presented in Figure 3, $B$ and $D$, began with the same population used in Figure 3, $A$ and $C$. We used a single trial of activity from each cell to estimate the previous goal (left panels) and the future goal (right panels) (see Materials and Methods). For each neural population size, with a "population" of one cell at the top and the total sample at the bottom, the previous goal was estimated relatively accurately (bright colors), especially for larger ensemble sizes. Although this subpopulation encoded previous goals reasonably accurately (Fig. 3, left panels), it showed no capacity to encode the locations of future goals (Fig. 3, right panels; see also supplemental Fig. $2 \mathrm{~A}$, available at www.jneurosci.org as supplemental material). Note the complementary nature of the population averages and the neuron-dropping analyses. The former (Fig. $3 A, C$ ) showed that although this subpopulation encoded previous-goal locations, it did not encode the same locations when they served as future goals. The latter (Fig. $3 B, D$ ) showed that this subpopulation did not encode any locations when they served as future goals. Supplemental Figure 3 (available at www. jneurosci.org as supplemental material) shows comparable data for a larger subpopulation of neurons, which included all cells indicated by ANOVA to have previous-goal selectivity but not future-goal (or hybrid) selectivity, regardless of the number of trials collected on second-chance trials. This increase in ensemble size allowed an improved estimate of the previous-goal location, as expected.

\section{Future-goal selectivity}

Figure 4 shows a different PF cell, one with selectivity for the future goal. It had its greatest activity when the future goal was to the right of the fixation point (Fig. $4 B$ ). The difference in activity on trials in which the future goal was to the right (the preferred future goal) and when it was to the left (the anti-preferred goal) is shown in Figure $4 B$ (bottom). This cell showed no selectivity for the previous goal (Fig. $4 A$ ).

Of the 827 neurons studied in this analysis (259 from monkey 1 and 569 from monkey 2), 105 (13\%) showed future-goal selectivity (29 in monkey 1 and 76 in monkey 2). Figure 5, $A$ and $C$, shows the population activity for cells encoding future goals, based on ANOVA. Because we eliminated hybrid cells, this subpopulation did not share any members with the subpopulation illustrated in Figure 3. Eliminating the hybrid cells reduced the size of the future-goal-selective cells to 20 and 64 in monkeys 1 and 2, respectively. Like the analysis in Figure 3, we evaluated whether this subpopulation might also have encoded spatial locations per se. Trials sorted according to the preferred and antipreferred locations in the Fix II period (Fig. 3, gray shading) clearly encoded future goals (right panel) but not previous ones (left panel). Neuron-dropping analyses yielded highly accurate estimations of future-goal locations but virtually no information about the previous goals (Fig. $5 B, D$ and supplemental Fig. $2 B$, available at www.jneurosci.org as supplemental material). In comparing previous-goal encoding (Fig. 3, left) and future-goal encoding (Fig. 5, right), the latter was stronger and more reliable (see also supplemental Fig. 2, $A$ vs $B$, available at www.jneurosci. org as supplemental material).

The data presented thus far show that one subpopulation of PF cells represented the previous-goal location but not the future-goal location. This analysis was performed on activity during the Fix I period, which occurred on first-chance trials of the strategy task (Figs. 2, 3). The data also show that a different subpopulation of PF cells represented the future goal but not the previous goal. This analysis was performed on activity during the Fix II period, which occurred on second-chance trials of the strategy task (Figs. 4, 5). To determine whether the difference depended on the previous versus future goal contrast or, alternatively, the first- versus second-chance trial contrast, we tested whether the cells classified as future-goal selective were also selective for the same goal in the mapping task and during the cue period of first-chance trials. We reasoned that cells encoding future-goal selectivity should encode that future goal in the mapping task as well as in the strategy task, and in first-chance trials as well as in second-chance trials. Figure 6 shows more data from the cell illustrated in Figure 4. This PF neuron was selective for a future goal to the right (Fig. $4 \mathrm{~B}$ ) on second-chance trials. It had the same future-goal preference both in first-chance trials (Fig. $6 \mathrm{~A}$ ) and in the mapping task (Fig. $6 \mathrm{~B}$ ). Figure $6 \mathrm{C}$ shows the close correspondence of goal tuning for both the first-chance trials 


\section{A}

First-chance trials sorted by future goal

\section{Strategy}

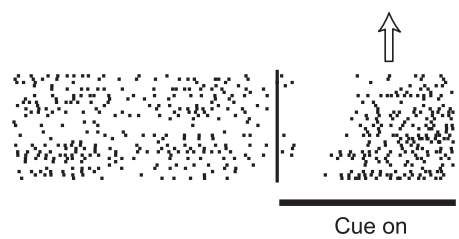

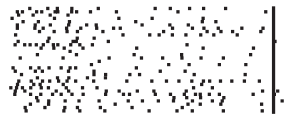

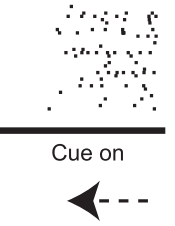

anti-preferred goal

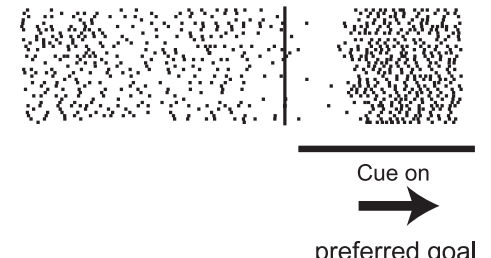

preferred goal
B

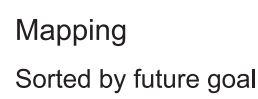

Sorted by future goal

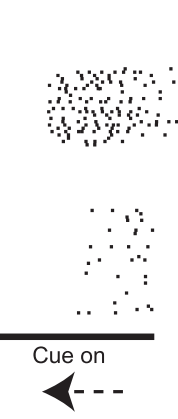

anti-preferred goal

of activity for the preferred future goal, as shown in Figure 7, $B$ and $D$. All of these correlations were highly statistically significant (Pearson's correlation moment; $p<$ 0.001).

\section{Relative frequency of previous-goal,} future-goal, and hybrid selectivity ANOVA revealed that $26 \%$ of the sampled neurons showed selectivity for goal location ( 66 of 259 cells and 147 of 568 cells in monkeys 1 and 2, respectively). Figure 8 shows that, of these, a large majority had either significant previous-goal selectivity (Fig. 2) or significant future-goal selectivity (Figs. 4, 6), but very few showed significant selectivity for both (Fig. 9). Of the goal-selective neurons, $46 \%$ showed selectivity for previous goals ( 37 and 71 cells in monkeys 1 and 2, respectively), and, despite a lower statistical power attributable to fewer second-chance trials, $45 \%$ did so for future goals (29 and 76 cells). A few neurons ( $9 \%$ ) showed a selectivity for both previous and future goals ( 9 and 12 cells in monkeys 1 and 2, respectively), and of these few hybrid cells, one-third shared the same preferred goal ( 3 of 9 and 4 of 12 cells in monkeys 1 and 2, respectively). The relatively small number of second-chance trials may have led to an underestimate of hybrid cells by limiting the number of neurons with detectable future-goal selectivity, but this was unlikely to be a major factor in the present results. Not only did $45 \%$ of the goal-selective sample show futuregoal selectivity without previous-goal selectivity, but future-goal selectivity was better encoded in the PF than was previous-goal selectivity (supplemental Fig. 2, available at www.jneurosci.org as supplemental material).

\section{Timing of signal development}

Figure 10, from monkey 2, shows that the subpopulation representing future goals began to do so $\sim 250-500 \mathrm{~ms}$ after the symbolic cue appeared on first-chance trials (Fig. $10 \mathrm{~B}$ ). The properties of cells with

(left) and for the mapping task (right). ANOVA and correlational analysis revealed this result to be reflective of the population. ANOVA showed that among the cells with future-goal selectivity in second-chance trials (Fix II period), many also had future-goal selectivity during first-chance trials of the strategy task [36 of 84 cells (43\%), both monkeys combined] and during the mapping task [39 of 70 cells $(56 \%)$ ]. A large majority of these had the same preferred goal $(81 \%$ of the 36 cells in first-chance trials of the strategy task and $74 \%$ of the 39 cells in the mapping task). Figure $7 A$ shows that the correlation in goal tuning, defined as the activity difference between preferred and anti-preferred goals, was $r=$ 0.79 for first- versus second-chance trials, and Figure $7 C$ shows a correlation of $r=0.78$ for the strategy versus mapping tasks. Similar values, $r=0.83$ and $r=0.91$, were obtained for the level previous-goal selectivity also evolved during the cue period: their selectivity gradually reduced after the symbolic cue appeared (Fig. 10A). Thus, after the cue appeared, the future-goal signal increased in its subpopulation as the previous-goal signal decreased in its subpopulation (Fig. 10C). Note also that the cells with future-goal selectivity for the first-chance trial (Fig. 10B) also showed future-goal selectivity for the second-chance trials (Fig. 10D), and this signal developed during or before the intertrial interval (Fig. 10D). This finding is not surprising because, as noted above, the monkey presumably made its decision about the future goal on second-chance trials soon after the first-chance trial ended without the delivery of a reward (Fig. 1 B3). As shown in Figure $10 D$, the future-goal signal persisted until after the 
2nd-chance trials vs. 1st-chance trials
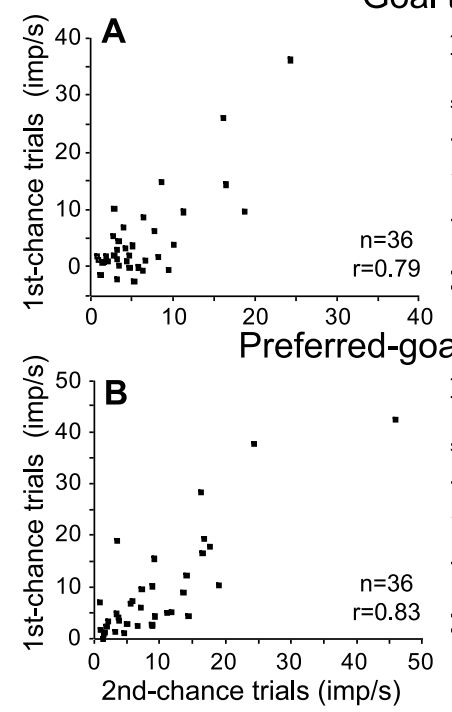

\section{Goal tuning}

2nd-chance trials vs. mapping task
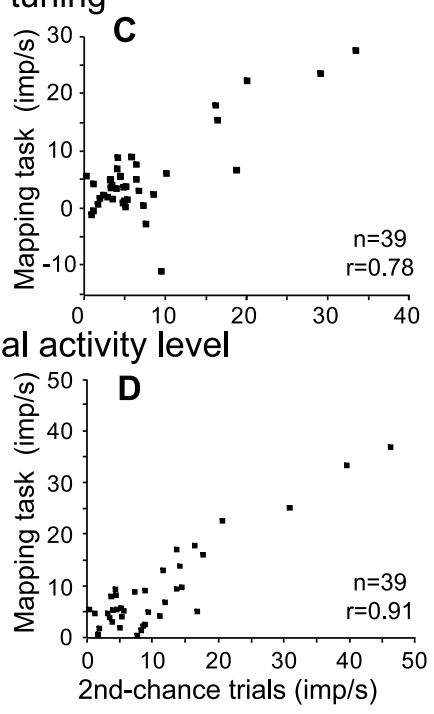

Figure 7. Future-goal selectivity in different tasks and trial types. Comparison of future-goal selectivity in the first-chance versus second-chance trials $(\boldsymbol{A}, \boldsymbol{B})$ and in the second-chance trials versus the mapping task $(\boldsymbol{C}, \boldsymbol{D})$. In all plots, the preferred direction was defined during the Fix II period of second-chance trials, and the abscissa shows the goal tuning of the cell during this period, defined as the difference in activity levels between the preferred and anti-preferred future goals. $A, C$, The ordinate shows goal tuning for first-chance trials $(\boldsymbol{A})$ and the mapping task ( $\boldsymbol{C}$, with the preferred goal matched to that used for the abscissa. $\boldsymbol{B}, \boldsymbol{D}$, In the format of $\boldsymbol{A}$ and $\boldsymbol{C}$, but showing the level of activity for the preferred goal rather than the tuning. imp, Impulses.
A

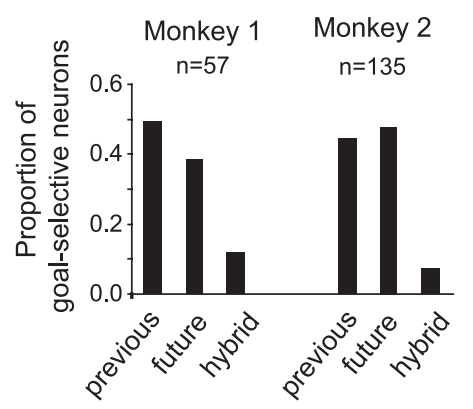

B

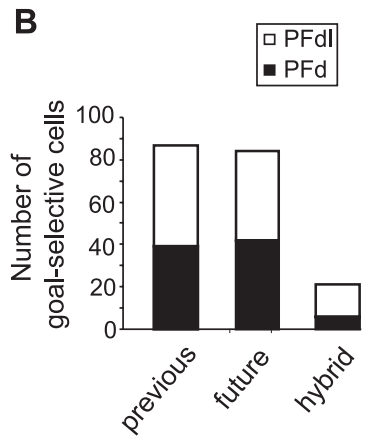

Figure 8. Population frequencies and counts. $A$, The proportion of PF neurons, by monkey, selective for previous goal, future goal, or both (hybrids). $\boldsymbol{B}$, Number of neurons in each class for the dorsal recording sites (PFd) and the dorsolateral ones (PFdl), as illustrated in Figure $1 C$.

monkey had chosen and acquired its goal and continued into the goal hold time. Data from monkey 1 were similar (supplemental Fig. 4, available at www.jneurosci.org as supplemental material).

\section{Relationship to strategy selectivity}

As reported previously (Genovesio et al., 2005), many PF cells encoded the repeat-stay strategy and others encoded the changeshift strategy, in approximately equal numbers. Although only a few PF cells shared selectivity for both previous and future goals (Fig. 8), many shared selectivity for both goals and strategies. Supplemental Table 1 (available at www.jneurosci.org as supplemental material) shows that $31 \%$ of the cells with previous-goal selectivity also showed strategy selectivity and $36 \%$ of the cells with future-goal selectivity did so.

Figure 11 shows a cell with selectivity for the change-shift strategy and the previous-goal location. The strategy selectivity of the cell is apparent from the difference in Fix I and cue-period activity for change trials (Fig. 11 $A, B$, left) versus repeat trials (Fig. $11 A, B$, right). Note that this cell, which is also illustrated in Figure 2 , showed no selectivity for future goals during these same, first-chance trials (Fig. 2C), which is not surprising given that this neuron also failed to show any future-goal selectivity during second-chance trials (Fig. $2 B$ ). Neurons with both strategy and goal selectivity, especially during the cue period, may have a role in linking a strategy to either previous or future goals. Neurons like that in Figure 10, which are selective for both the change-shift strategy and the previous goal, may be related to the shift from a given goal. Similarly, neurons selective for both the change-shift strategy and the future goal (data not shown) may be related to the shift to a goal.

\section{Error analysis}

For the error analysis, we used data only from monkey 2 because we recorded fewer trials of the activity of each neuron in monkey 1 , which led to a small number of error trials. The activity during erroneously performed second-chance trials reflected the goal the monkeys chose and not the one they should have chosen. Thus, when the trials were sorted by the goal actually selected (Fig. 12), the overall activity preferences remained the same on error trials (dashed lines) as on correct trials (solid lines). This finding shows that the cells in Figure 5 represented the future goal selected rather than a more abstract computation of the correct one.

\section{Lack of selectivity for the symbolic cue}

We also searched for neurons selective for the symbolic cue from the previous trial. Two-way ANOVA, with the previous goals and cues as factors, detected cue selectivity at approximately the frequency expected for false-positive errors $(\alpha=0.05)$. In monkey $1,4 \%$ of the cells with data adequate for testing (at least 10 trials for each goal in first chance trials; 27 of 628 neurons) showed an effect of the cue. In monkey 2, 5\% (38 of 705 neurons) did so. These minimal frequencies contrast with the 15\% (96 of 628 neurons) and $11 \%$ ( 81 of 705 neurons), in monkey 1 and monkey 2 , respectively, that were selective for the previous goal, for example. Neuron-dropping analysis showed a very weak estimation of the symbolic cues, even in cells with significant cue effects (supplemental Fig. 5, available at www.jneurosci.org as supplemental material). This finding indicates that even this highly selected group of cells had only a poor ability to encode the previous symbolic cue.

\section{Discussion}

We found that essentially separate subpopulations of PF neurons encode previous and future goals. We emphasize that other areas may share this property, and there is no attempt here to distinguish among goals per se, the motor plans needed to achieve those goals or the intention to do so. Nevertheless, the segregation between neuronal subpopulations representing previous and future goals is likely to be important for many daily life activities, in which goals, plans, and intentions remain unfulfilled for a time. This segregation could contribute to monitoring which goals have been accomplished and which remain pending, sometimes called output monitoring. Prematurely representing an intended goal as already accomplished would lead to omissions. Repetitive and habitual tasks, such as taking medication periodically, are prone to this problem (Einstein et al., 2000; Marsh et al., 2002; Maylor et al., 2002; Elvevåg et al., 2003), which 
A

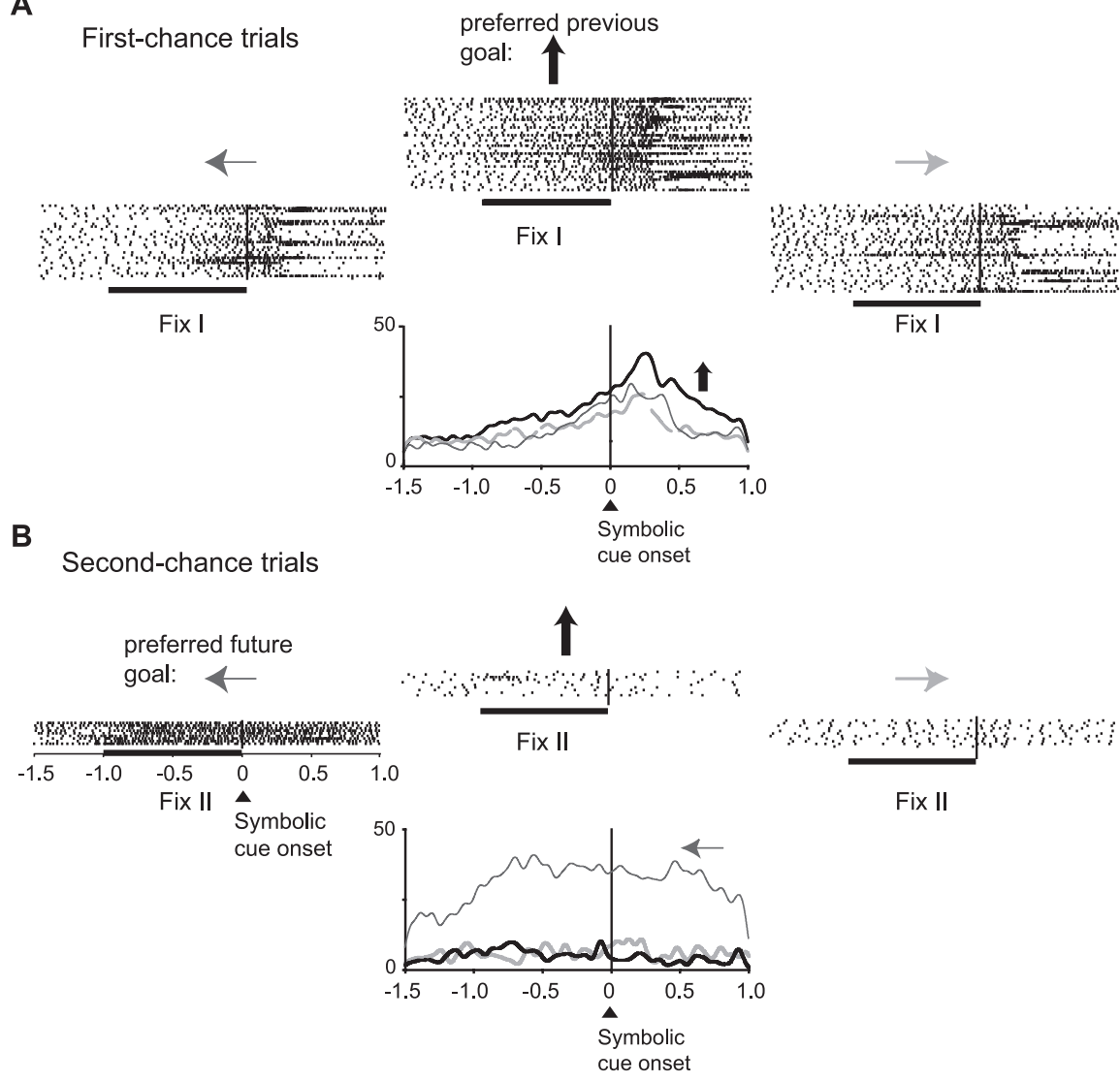

Figure 9. A hybrid cell. Raster and histogram displays for a PF neuron with significant selectivity for both the previous and future goals. The format is as in Figure 2.

occurs in normal aging (Einstein et al., 2000), schizophrenia (Elvevåg et al., 2003), and Alzheimer's disease (Maylor et al., 2002). Conversely, misrepresenting an already accomplished goal as still pending would lead to repetition, and such perseveration is well known in PF dysfunction (Milner, 1963). In marmosets, for example, PF lesions lead to perseveration in a spatialstrategy task (Collins et al., 1998). A related consequence could be compulsively checking whether a goal has been accomplished, and dysfunction of dorsal PF is thought to contribute to this form of obsessive-compulsive disorder (Mataix-Cols et al., 2004).

\section{Interpretational issues}

As noted above, we could not distinguish neural signals for future goals from those for motor plans or intentions to achieve those goals, nor could we rule out attention effects. During the Fix II period, future goals were likely targets of covert attention, and this could have accounted for future-goal selectivity. This interpretation agrees with recent work demonstrating that most delay-period activity in the PFdl reflects attentional rather than mnemonic processes (Lebedev et al., 2004).

Another issue involves our assumption that the monkeys had chosen their future goals before the Fix II period. The symbolic cue was irrelevant on second-chance trials, and the monkeys could select their future goal as soon as the nonreward event terminated a first-chance trial (Fig. $1 A, B$ ). We assume that they did so before the Fix II period. During error trials, the spatially selective activity reflected the goal that the monkey actually chose rather than the goal that should have been chosen (Fig. 12). The time course over which the future-goal-selective signal developed
(Figs. 10D, 12) supports the idea that the choice had occurred before the Fix II period. Figure $10 B$ further supports this conclusion by showing that cells selective for future goals on second-chance trials also encoded future goals on first-chance trials, soon after the cue appeared.

An alternative interpretation for the future-goal selectivity in the Fix II period is that it might reflect a memory for the two previous goals, combined. We can reject this alternative for the cells that maintain the same future-goal selectivity in firstchance trials and in the mapping task (Figs. 6, 7). In neither case was the monkey required to remember both of the two most recent goals. Furthermore, in incorrectly performed second-chance trials, activity reflected the goal that was chosen and not the correct one (Fig. 12). Behavioral evidence shows that the errors almost invariably involved failing to reject the goal before the most recent one, probably because it had been forgotten (Genovesio at al. 2005). A signal reflecting the memory of both previous goals should have differed when one was forgotten.

\section{Comparison with previous studies}

The present results are consistent with ideas about PF function that invoke the monitoring of information in a short-term memory buffer, as observed in selfordering tasks in which monkeys or humans must keep previously chosen objects in memory to select future ones (Owen et al., 1996, 1999; Hasegawa et al., 2004). Indeed, an aspect of the present task can be viewed as a sophisticated, spatial form of the self-ordered task. The present data are also consistent with neurophysiological evidence that PF neurons encode both intermediate and final goals (Saito et al., 2005). The role of the PF in encoding information about future events has considerable neuroimaging (Okuda et al., 1998; Bunge et al., 2001, 2004; Pochon et al., 2001; Volle et al., 2005) and neurophysiological (Rainer et al., 1999; Mushiake et al., 2006) support, and the coding of future goals described here supports these findings.

PF performs several important functions, including categorization (Freedman et al., 2002), prospective coding (Rainer et al., 1999), task selection (Hoshi et al., 1998; Asaad et al., 2000), attention control (Miller et al., 1996; Lebedev et al., 2004), shortterm memory (Funahashi et al., 1989, 1993; Quintana and Fuster, 1993; Wilson et al., 1993; Goldman-Rakic, 1996; Owen et al., 1996; Rao et al., 1997; Rainer et al., 1998; Constantinidis et al., 2001; Rowe and Passingham, 2001; Petrides et al., 2002; Rowe et al., 2002; Lau et al., 2004; Takeda and Funahashi, 2004), implementation of rules and strategies (Hoshi et al., 2000; Bunge et al., 2003; Wallis and Miller, 2003; Barraclough et al., 2004; Genovesio et al., 2005), and event sequencing (Quintana and Fuster, 1999; Averbeck et al., 2002; Ninokura et al., 2003, 2004; Hoshi and Tanji, 2004). In the present study, we show that one subpopulation has activity that reflects the previous and not the future goal, whereas an essentially separate subpopulation has the opposite properties.

Most previous neurophysiological studies have cued a re- 
sponse on a trial-by-trial basis (Quintana and Fuster, 1999; Rainer et al., 1999; Fuster et al., 2000; Hoshi et al., 2000) (see also citations in the Introduction), and so there was no need to remember the previous goal. In such tasks, coding for the future goal, in a "motor" sense, has been ruled out for the majority of PF cells on the basis of their encoding sensory parameters (Romo et al., 1999; Constantinidis et al., 2001) or when a cue in one location instructed a future response to some other location (Funahashi et al., 1993; Takeda and Funahashi, 2002, 2004; Fukushima et al., 2004). But these conclusions have no bearing on the short-term storage of information about a location as a future versus a previous goal, because in none of these studies did such goals need to be maintained in different delay periods of the task, as in the present study. In the study by Barraclough at al. (2004), monkeys needed to monitor previous responses to maximize their success rate. Both previous and future goals, however, were processed in all task periods. In our paradigm, however, the representation of the future goal was precluded during the task period, Fix I, when monkeys remembered the previous goal.

\section{Submodality segregation}

To perform the task, the monkeys had to remember both the previous goal and the previous symbolic cue. This feature of the task allowed us to address submodality segregation within PF. Some previous studies have supported a regional segregation between ventrolateral PF regions processing the nonspatial information of a cue and dorsolateral PF regions processing its spatial information (Wilson et al., 1993; Levy and Goldman-Rakic, 2000), but others have presented strong evidence against this conclusion (Rao et al., 1997; Rainer et al., 1998). In the neurons sampled here, mainly in the PFdl and PFd (Fig. 1C), we saw no selectivity for nonspatial information during either the Fix I (supplemental Fig. 5, available at www.jneurosci.org as supplemental material) or Fix II periods. We emphasize that we did observe cue selectivity (Genovesio et al., 2005), but mainly when the cues were visible, not during the fixation periods before the cues, when the previous cue must have been in memory. The lack of cue selectivity during these fixation periods suggests that nonspatial information, which was required for the strategies used, was maintained by another neural network. The ventrolateral $\mathrm{PF}$, which has been shown to maintain object information in delayed matching-to-

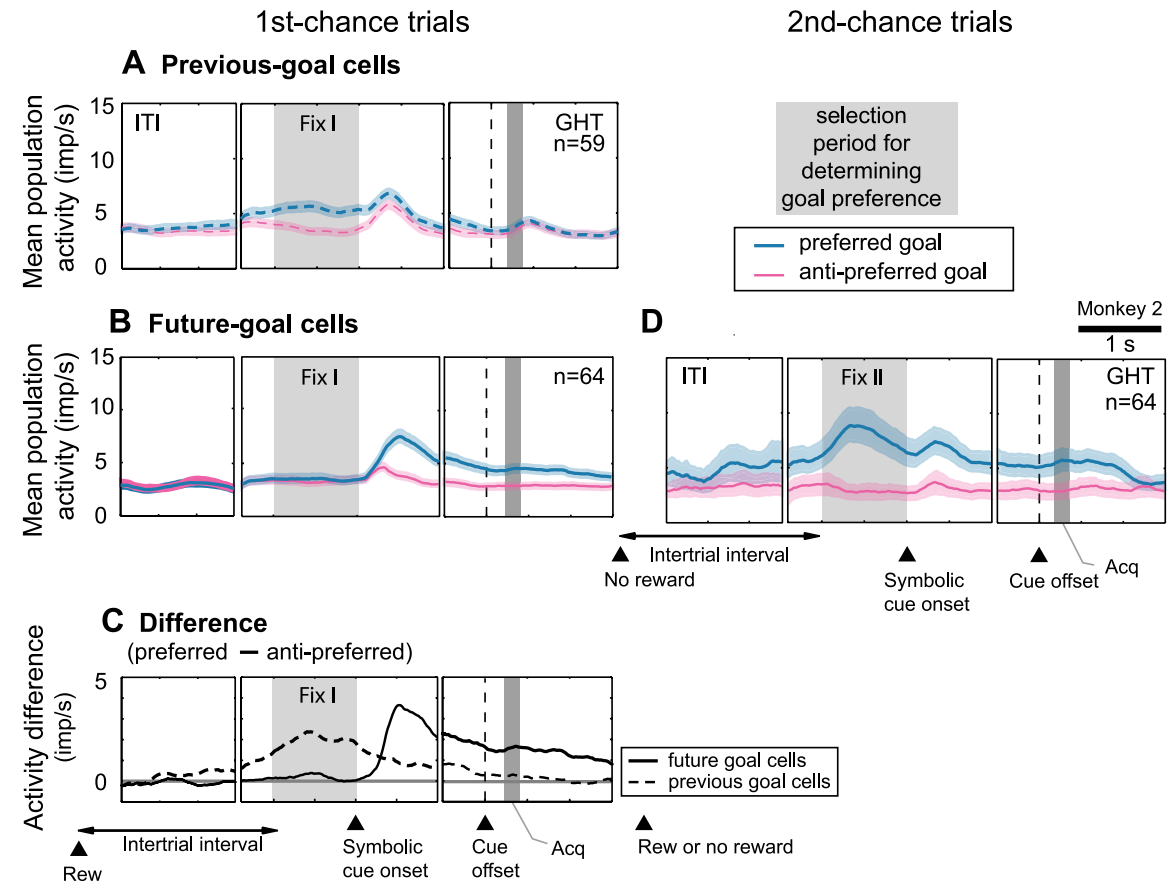

Figure 10. Time course of previous- and future-goal selectivity. A, Average activity of the subpopulation selective for the previous-goal location, in the format of Figure $3 A$. Note that the previous-goal selectivity decreased during the first part of the symbolic-cue period and was not observable during the preceding intertrial interval or subsequent parts of first-chance trials. $\boldsymbol{B}$, In the format of $A$, but for the subpopulation selective for the future-goal location. $C$, Difference between the preferred and anti-preferred goals, from $\boldsymbol{A}$ (dashed line) and $\boldsymbol{B}$ (solid line). $\boldsymbol{D}$, In the format of $\boldsymbol{A}$, but for future-goal cells during second-chance trials. The same subpopulation as in $\boldsymbol{B}$ is shown. Note that selectivity for future goals appeared during the intertrial interval, increased during the Fix II period, increased again after the onset of the symbolic cue, and continued through cue offset, goal acquisition, and the first part of the goal hold time. The shaded gray rectangle labeled Acq corresponds to \pm 1 SD of the mean. Data are from monkey 2; analogous data for monkey 1 appears in supplemental Figure 4 (available at www.jneurosci.org as supplemental material). imp, Impulses; ITI, intertrial interval; Acq, goal acquisition; GHT, goal hold time; Rew, reward.

A Change trials $\quad \begin{gathered}\text { sorted by } \\ \text { previous goal }\end{gathered}$
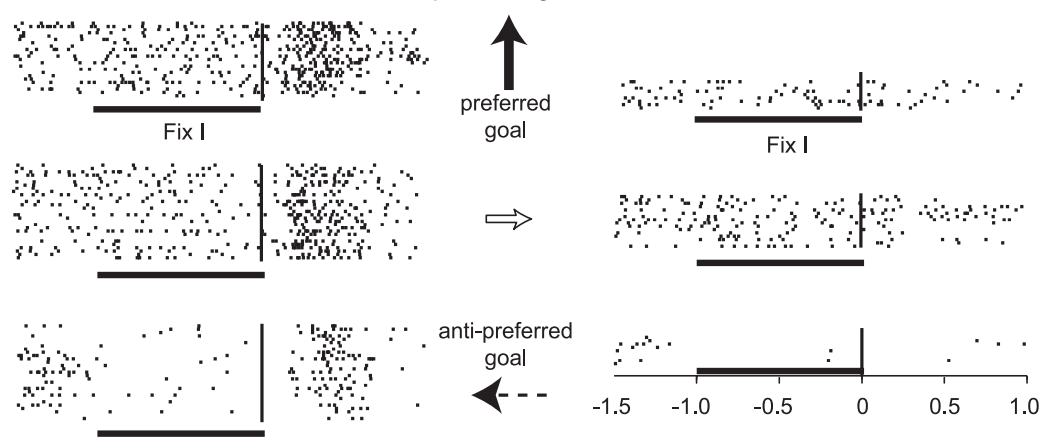

B

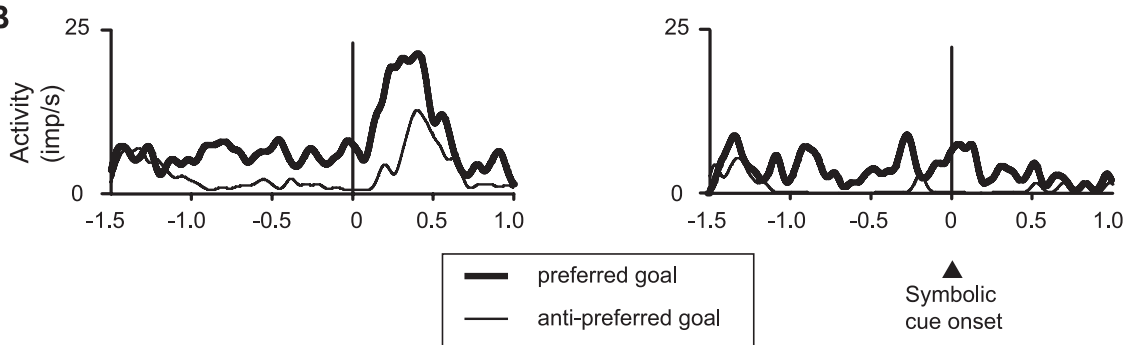

Figure 11. Previous-goal representation in a strategy-selective cell. The same neuron as in Figure 2 is shown. $\boldsymbol{A}$, Left column, Raster displays for change trials. Right column, Repeat trials. The cell showed a preference for trials in which the top goal had been selected previously, but only on change trials. B, Activity averages for the preferred (solid arrow) and anti-preferred (dashed arrow) goals from $\boldsymbol{A}$ in each column. The cell is both strategy- and previous-goal selective and has a significant interactive effect between the factors strategy and previous goal during the cue period. imp, Impulses. 


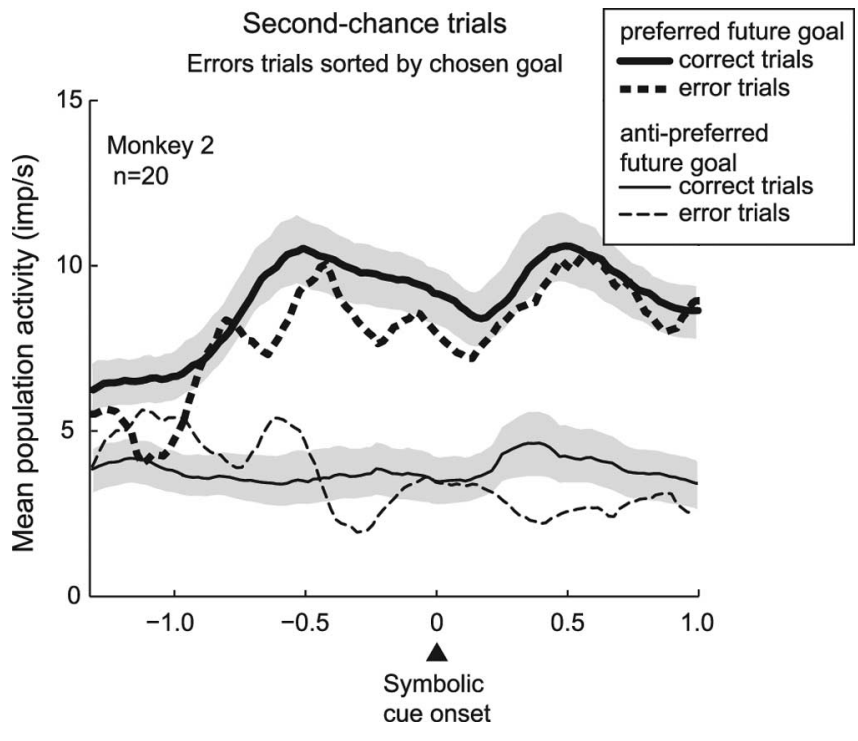

Figure 12. Error analysis. Average population activity showing that the goal selectivity is for the chosen goal and not for the goal that should have been chosen. Data are from monkey 2. When trials were sorted according to the goal the monkey eventually selected, the goal selectivity on error trials (dashed lines) closely corresponded to that on correct trials (solid lines) for both the preferred (thick lines) and anti-preferred (thin lines) goals. imp, Impulses.

sample tasks (Miller et al., 1996), seems a likely candidate. Our results thus provide some support for the idea that, under certain circumstances, PFdl and PFd monitors mainly spatial information. Future studies might address the role of the ventrolateral PF under the same circumstances.

\section{Conclusions}

The PF has been viewed as a neural substrate for goal representations, including abstract goals such as adherence to rules and strategies (Owen et al., 1990, 1996; Collins et al., 1998; Robbins, 2000; Gaffan et al., 2002; Rushworth et al., 2002; Brass et al., 2003; Bunge et al., 2003; Bunge, 2004). To perform this function efficiently, its neural networks must differentiate accomplished goals from those that have not yet been attained. Our results suggest that separate subpopulations of neurons, intermingled within the $\mathrm{PF}$, perform these two functions. More generally, the previous goal can be viewed as one of the essential source materials for a neural computation that produces a future goal as its end product. Future work might examine whether our conclusions about spatial goals generalize to nonspatial goals and, even further, to all starting materials and end products of neural computations.

\section{References}

Asaad WF, Rainer G, Miller EK (1998) Neural activity in the primate prefrontal cortex during associative learning. Neuron 21:1399-1407.

Asaad WF, Rainer G, Miller EK (2000) Task-specific neural activity in the primate prefrontal cortex. J Neurophysiol 84:451-459.

Averbeck BB, Chafee MV, Crowe DA, Georgopoulos AP (2002) Parallel processing of serial movements in prefrontal cortex. Proc Natl Acad Sci USA 99:13172-13177.

Barraclough DJ, Conroy ML, Lee D (2004) Prefrontal cortex and decision making in a mixed-strategy game. Nat Neurosci 7:404-410.

Brass M, Ruge H, Meiran N, Rubin O, Koch I, Zysset S, Prinz W, von Cramon DY (2003) When the same response has different meanings: recoding the response meaning in the lateral prefrontal cortex. NeuroImage 20:1026-1031.

Bunge SA (2004) How we use rules to select actions: a review of evidence from cognitive neuroscience. Cogn Affect Behav Neurosci 4:564-579.

Bunge SA, Ochsner KN, Desmond JE, Glover GH, Gabrieli JDE (2001) Pre- frontal regions involved in keeping information in and out of mind. Brain 124:2074- 2086.

Bunge SA, Kahn I, Wallis JD, Miller EK, Wagner AD (2003) Neural circuits subserving the retrieval and maintenance of abstract rules. J Neurophysiol 90:3419-3428.

Bunge SA, Burrows B, Wagner AD (2004) Prefrontal and hippocampal contributions to visual associative recognition: interactions between cognitive control and episodic retrieval. Brain Cogn 56:141-152.

Collins P, Roberts AC, Dias R, Everitt BJ, Robbins TW (1998) Perseveration and strategy in a novel spatial self-ordered sequencing task for nonhuman primates: effects of excitotoxic lesions and dopamine depletions of the prefrontal cortex. J Cogn Neurosci 10:332-354.

Constantinidis C, Franowicz MN, Goldman-Rakic PS (2001) The sensory nature of mnemonic representation in the primate prefrontal cortex. Nat Neurosci 4:311-316.

Einstein GO, McDaniel MA, Manzi M, Cochran B, Baker M (2000) Prospective memory and aging: forgetting intentions over short delays. Psychol Aging 15:671-683.

Elvevåg B, Maylor EA, Gilbert AL (2003) Habitual prospective memory in schizophrenia. BMC Psychiatry 3:9.

Foffani G, Moxon KA (2004) PSTH-based classification of sensory stimuli using ensembles of single neurons. J Neurosci Methods 135:107-120.

Freedman DJ, Riesenhuber M, Poggio T, Miller EK (2002) Visual categorization and the primate prefrontal cortex: neurophysiology and behavior. J Neurophysiol 88:929-941.

Fukushima T, Hasegawa I, Miyashita Y (2004) Prefrontal neuronal activity encodes spatial target representations sequentially updated after nonspatial target-shift cues. J Neurophysiol 91:1367-1380.

Funahashi S, Bruce CJ, Goldman-Rakic PS (1989) Mnemonic coding of visual space in the monkey's dorsolateral prefrontal cortex. J Neurophysiol 61:331-349.

Funahashi S, Chafee MV, Goldman-Rakic PS (1993) Prefrontal neuronal activity in rhesus monkeys performing a delayed anti-saccade task. Nature 365:753-756.

Fuster JM, Alexander GE (1971) Neuron activity related to short-term memory. Science 173:652-654.

Fuster JM, Bodner M, Kroger JK (2000) Cross-modal and cross-temporal association in neurons of frontal cortex. Nature 405:347-351.

Gaffan D, Easton A, Parker A (2002) Interaction of inferior temporal cortex with frontal cortex and basal forebrain: double dissociation in strategy implementation and associative learning. J Neurosci 22:7288-7296.

Genovesio A, Brasted PJ, Mitz AR, Wise SP (2005) Prefrontal cortex activity related to abstract response strategies. Neuron 47:307-320.

Goldman-Rakic PS (1996) Regional and cellular fractionation of working memory. Proc Natl Acad Sci USA 93:13473-13480.

Hasegawa RP, Blitz AM, Goldberg ME (2004) Neurons in monkey prefrontal cortex whose activity tracks the progress of a three-step self-ordered task. J Neurophysiol 92:1524-1535.

Hoshi E, Tanji J (2004) Area-selective neuronal activity in the dorsolateral prefrontal cortex for information retrieval and action planning. J Neurophysiol 91:2707-2722.

Hoshi E, Shima K, Tanji J (1998) Task-dependent selectivity of movementrelated neuronal activity in the primate prefrontal cortex. J Neurophysiol 80:3392-3397.

Hoshi E, Shima K, Tanji J (2000) Neuronal activity in the primate prefrontal cortex in the process of motor selection based on two behavioral rules. J Neurophysiol 83:2355-2373.

Kim JN, Shadlen MN (1999) Neural correlates of a decision in the dorsolateral prefrontal cortex of the macaque. Nat Neurosci 2:176-185.

Kojima S, Goldman-Rakic PS (1982) Delay-related activity of prefrontal neurons in rhesus monkeys performing delayed response. Brain Res 248:43-49.

Lau HC, Rogers RD, Ramnani N, Passingham RE (2004) Willed action and attention to the selection of action. NeuroImage 21:1407-1415.

Laubach M, Wessberg J, Nicolelis MA (2000) Cortical ensemble activity increasingly predicts behaviour outcomes during learning of a motor task. Nature 405:567-571.

Lebedev MA, Messinger A, Kralik JD, Wise SP (2004) Representation of attended versus remembered locations in prefrontal cortex. PLoS Biol 2:1919-1935.

Levy R, Goldman-Rakic PS (2000) Segregation of working memory functions within the dorsolateral prefrontal cortex. Exp Brain Res 133:23-32. 
Marsh RL, Hicks JL, Hancock TW, Munsayac K (2002) Investigating the output monitoring component of event-based prospective memory performance. Mem Cogn 30:302-311.

Mataix-Cols D, Wooderson S, Lawrence N, Brammer MJ, Speckens A, Phillips ML (2004) Distinct neural correlates of washing, checking, and hoarding symptom dimensions in obsessive-compulsive disorder. Arch Gen Psychiatry 61:564-576.

Maylor EA, Smith G, Della SS, Logie RH (2002) Prospective and retrospective memory in normal aging and dementia: an experimental study. Mem Cogn 30:871-884.

Miller EK, Erickson CA, Desimone R (1996) Neural mechanisms of visual working memory in prefrontal cortex of the macaque. J Neurosci 16:5154-5167.

Milner B (1963) Effects of different brain lesions on card sorting: the role of the frontal lobes. Arch Neurol 9:90-100.

Mushiake H, Saito N, Sakamoto K, Itoyama Y, Tanji J (2006) Activity in the lateral prefrontal cortex reflects multiple steps of future events in action plans. Neuron 50:631-641.

Niki H (1974a) Prefrontal unit activity during delayed alternation in the monkey. I. Relation to direction of response. Brain Res 68:185-196.

Niki H (1974b) Prefrontal unit activity during delayed alternation in the monkey. II. Relation to absolute versus relative direction of response. Brain Res 68:197-204.

Ninokura Y, Mushiake H, Tanji J (2003) Representation of the temporal order of visual objects in the primate lateral prefrontal cortex. J Neurophysiol 89:2868-2873.

Ninokura Y, Mushiake H, Tanji J (2004) Integration of temporal order and object information in the monkey lateral prefrontal cortex. J Neurophysiol 91:555-560.

Okuda J, Fujii T, Yamadori A, Kawashima R, Tsukiura T, Fukatsu R, Suzuki K, Ito M, Fukuda H (1998) Participation of the prefrontal cortices in prospective memory: evidence from a PET study in humans. Neurosci Lett 253:127-130.

Owen AM, Downes JJ, Sahakian BJ, Polkey CE, Robbins TW (1990) Planning and spatial working memory following frontal lobe lesions in man. Neuropsychologia 28:1021-1034.

Owen AM, Evans AC, Petrides M (1996) Evidence for a two-stage model of spatial working memory processing within the lateral frontal cortex: a positron emission tomography study. Cereb Cortex 6:31-38.

Owen AM, Herrod NJ, Menon DK, Clark JC, Downey SP, Carpenter TA, Minhas PS, Turkheimer FE, Williams EJ, Robbins TW, Sahakian BJ, Petrides M, Pickard JD (1999) Redefining the functional organization of working memory processes within human lateral prefrontal cortex. Eur J Neurosci 11:567-574.

Pasupathy A, Miller EK (2005) Different time courses for learning-related activity in the prefrontal cortex and striatum. Nature 433:873-876.

Petrides M, Alivisatos B, Frey S (2002) Differential activation of the human orbital, midventrolateral, and mid-dorsolateral prefrontal cortex during the processing of visual stimuli. Proc Natl Acad Sci USA 99:5649-5654.

Pochon JB, Levy R, Poline JB, Crozier S, Lehericy S, Pillon B, Deweer B, Lebihan D, Dubois B (2001) The role of dorsolateral prefrontal cortex in the preparation of forthcoming actions: an fMRI study. Cereb Cortex 11:260-266.

Quintana J, Fuster JM (1993) Spatial and temporal factors in the role of prefrontal and parietal cortex in visuomotor integration. Cereb Cortex 3:122-132.

Quintana J, Fuster JM (1999) From perception to action: temporal integrative functions of prefrontal and parietal neurons. Cereb Cortex 9:213-221.

Rainer G, Asaad WF, Miller EK (1998) Memory fields of neurons in the primate prefrontal cortex. Proc Natl Acad Sci USA 95:15008-15013.

Rainer G, Rao SC, Miller EK (1999) Prospective coding for objects in primate prefrontal cortex. J Neurosci 19:5493-5505.

Rao SC, Rainer G, Miller EK (1997) Integration of what and where in the primate prefrontal cortex. Science 276:821-824.

Robbins TW (2000) Chemical neuromodulation of frontal-executive functions in humans and other animals. Exp Brain Res 133:130-138.

Romo R, Brody CD, Hernandez A, Lemus L (1999) Neuronal correlates of parametric working memory in the prefrontal cortex. Nature 399:470-473.

Rowe J, Friston K, Frackowiak R, Passingham R (2002) Attention to action: specific modulation of corticocortical interactions in humans. NeuroImage 17:988-998.

Rowe JB, Passingham RE (2001) Working memory for location and time: activity in prefrontal area 46 relates to selection rather than maintenance in memory. NeuroImage 14:77-86.

Rushworth MFS, Hadland KA, Paus T, Sipila PK (2002) Role of the human medial frontal cortex in task switching: a combined fMRI and TMS study. J Neurophysiol 87:2577-2592.

Saito N, Mushiake H, Sakamoto K, Itoyama Y, Tanji J (2005) Representation of immediate and final behavioral goals in the monkey prefrontal cortex during an instructed delay period. Cereb Cortex 15:1535-1546.

Sawaguchi T, Yamane I (1999) Properties of delay-period neuronal activity in the monkey dorsolateral prefrontal cortex during a spatial delayed matching-to-sample task. J Neurophysiol 82:2070-2080.

Takeda K, Funahashi S (2002) Prefrontal task-related activity representing visual cue location or saccade direction in spatial working memory tasks. J Neurophysiol 87:567-588.

Takeda K, Funahashi S (2004) Population vector analysis of primate prefrontal activity during spatial working memory. Cereb Cortex 14:1328-1339.

Volle E, Pochon JB, Lehericy S, Pillon B, Dubois B, Levy R (2005) Specific cerebral networks for maintenance and response organization within working memory as evidenced by the "double delay/double response" paradigm. Cereb Cortex 15:1064-1074.

Wallis JD, Miller EK (2003) From rule to response: neuronal processes in the premotor and prefrontal cortex. J Neurophysiol 90:1790-1806.

White IM, Wise SP (1999) Rule-dependent neuronal activity in the prefrontal cortex. Exp Brain Res 126:315-335.

Wilson FAW, O’Scalaidhe P, Goldman-Rakic PS (1993) Dissociation of object and spatial processing domains in primate prefrontal cortex. Science 260:1955-1958. 